\title{
On Power and Participation: Reflections from design with developmentally diverse children
}

\author{
Asimina Vasalou, UCL Knowledge Lab, University College London, UK \\ Seray Ibrahim, UCL Knowledge Lab, University College London, UK \\ Michael Clarke, Department of Language and Cognition, University College London, UK \\ Yvonne Griffiths, School of Education, University of Leeds, Leeds, UK
}

\begin{abstract}
The involvement of developmentally diverse children in design has been driven by pragmatic concerns and also an emancipatory aim to give children voice and agency over decisions. However, little attention has been given to how participation and power are performed in the early exploratory phase of design prior to overt decision points. Our research seeks to contribute to this gap with two separate case studies of design involvement, one with dyslexic children and the other with children with cerebral palsy. An analysis of children's and researchers' power dynamics during design sessions supports us to understand the contextual factors shaping how the different participants exercised power; the outcomes of this power and to reflect on how these moments shaped the design agenda. Our work identifies a number of challenges and raises new questions that may guide future reflexive participatory practice with developmentally diverse children.
\end{abstract}

\section{INTRODUCTION}

The importance of hearing and acting on what children say is a central priority in legislative policy internationally $[15,48]$. According to recommendations from the UN Convention on the Rights of the Child [48] and also article 24 of the Charter of Fundamental Rights of the European Union [15], children have the right to be heard and consulted on all issues that affect them. With this guidance, there has been growing recognition that all children, including developmentally diverse children who may have special needs or disabilities, are experts in their own right who can and should contribute to decisions that directly impact on their lives [39]. Developmentally diverse children, including children who have dyslexia or cerebral palsy, have different experiences that shape the ways they interact with others. Connected with their cognitive and motor impairments, their opportunities for socialising, participation and learning can be highly limited. For these children, technologies can be life changing in providing supports for communication and learning, and it is for this reason that a strong stream of research has focused on developing technologies that support children's functional skills (see [19]) in what has been described as an 'enablement agenda' [14]. Yet, the ongoing high abandonment rate for assistive technologies [29,38] raises concerns about the extent to which they reflect children's priorities whilst also highlighting why children must be involved in design.

One of the underlying pillars of participatory design (PD) is to support marginalized voices by democratising having a say [45]. PD in the field of child-computer interaction has made important methodological contributions by investigating what forms child participation may take. Given its strong focus on methods, however, this work has not considered developmentally diverse children's power in design as a focal point, although a meta-review pointed out a lack of clarity over how children's participation shapes design [4]. Moreover, the same review showed that the participation of such children 
has largely been mitigated in the early phase of the design process, and thus opportunities exist for understanding how developmentally diverse children's participation can inform the early development of the design agenda.

In order to tackle these concerns, our paper critically considers how developmentally diverse children inform the early 'problem setting' phase of design through the theoretical lens of power. We present two separate case studies of design involvement for technology that supports children's functional skills, one with dyslexic children and the other with children with cerebral palsy. The inclusion of two very different groups of children provides an opportunity to consolidate and also differentiate our account of power. In pace with developments in broader participatory research that have adopted a reflexive stance for considering the multiple ways that power can be enacted [20], our analysis reveals instances of how power is exercised. The paper makes three contributions. First, we show a set of relational child-researcher behaviours particular to design research with developmentally diverse children, which can alert future researchers to recognize power dynamics with this population. Second, we identify and problematize a multifaceted set of factors that can contribute to how children and researchers negotiate power, leading to methodological implications for orchestrating design with developmentally diverse children. Third, we reflect on the consequences of particular power dynamics on children's empowerment in order to raise new considerations about empowering children whilst at the same time accomplishing the goals of the enablement agenda.

\section{BACKGROUND}

\section{Design for developmentally diverse children}

A review in the field of child-computer interaction suggests that technologies for developmentally diverse children have often been designed to support children's functional skills [4]. Most of the examples identified in the review took a remedial lens, approaching technology as a way to teach skills for which children needed particular support. Examples included a motion game for fostering the social initiation skills of children with autism [33], a game for reasoning skills for children with language comprehension difficulties [11], or a communication device for supporting expressive communication and improving the language skills of children with cerebral palsy who have little or no functional speech [17]. By approaching technology as a positive intervention that can increase social inclusion and learning, this past research has aligned itself with broader developments in the field of participatory design (PD). Whereas PD once provided a forum to challenge oppressive systems in the workplace, in recent years, it has been used to support an enablement agenda that seeks to intervene and change people's social conditions for the better following a social logic [14].

Focusing on autism as a critical case, Mankoff et al. [34] draw on critical disability research to challenge and 'reframe' such interventions away from considering the child as responsible for learning the behaviours of neurotypical people, to a situation where both interlocutors learn how to shape the alignment of their joint communication. Though Mankoff's work is critical of the logic underpinning the enablement agenda, other research has just started to challenge the predominant focus of technology design to support functional skills for developmentally diverse children. Frauenberger [57] builds on this perspective by inviting design researchers to apply a critical realist perspective that considers the wide ranging and situated motivations, methodologies, evaluation criteria, epistemology and ethics that guides assistive technology design agendas. In related work exemplifying how this can be approached, the same author [19] designed smart objects with and for children with autism with the explicit aim to move away from a functional focus, for instance by designing technology to support children's sensemaking of their everyday interactions. In a similar vein, Durrant et al [13] created a digital photograph sharing tool to engage a mixed ability group of children with special needs in regulated self-expression and sharing. 


\section{Children's power in participatory research and design}

The aforementioned technologies have often been supported through children's participation in design. Developmentally diverse children's design involvement, in particular, has been conceived as a means for gaining research insights that support the design of more appropriate technology, and as a democratic imperative [4]. When designing digital technology for and with children, a number of frameworks for planning child participation have been proposed. The most influential one is Druin's [12] cooperative inquiry, which describes different relationships researchers can plan for with children, spanning from user, tester, informant, and partner. By employing roles that define levels of participation, some researchers have proposed that more involved roles increase children's power in the design process (e.g. [27]). Others have used benchmarks of power to evaluate the quality of children's participation in design (e.g. [58]). The assumption, however, that power can be planned for and given as a commodity to children through frameworks of participation has been strongly contested. Gallagher's [21] reflexive analysis of participatory research with children illustrates this. Adopting the emancipatory ethics of the participatory tradition, Gallagher engaged children in focus groups combined with creative methods to explore their views of social space. At the same time as seeking to foster child agency and voice, he frequently found himself gently coaxing children who declined to engage with the research tasks. During the research he also reported problematic interactions in which the voices of dominant male children suppressed the voice of a timid female child. Similar findings were also reported by Iivari et al [2015] whilst designing new digital portfolio technology with children in a school context. Realising that a commodity perspective on power was limited in explaining these observations, Gallagher [20,21] drew on Foucault who defined power as a 'mode of action upon the action of others' (pg. 341) [18] to propose a sociological grounding for his research reflections. In line with this, Gallagher argues that any manifestation of power is specific, situated and constructed in its context. Applying Foucault's non-deterministic view on power, Gallagher proposes that actions must be appraised in context to understand if their effects are positive or negative. Moreover, recognising that power emerges from a network of different actor relations, Gallagher draws attention to the nested networks implicated in participatory activities with children shaping how power plays out, e.g., the gatekeepers who give access to child participants, children's interactions with one another during the participatory work, and so on. The view that power is contextual, dynamic and relational highlights a focus away from frameworks that plan participation in order to give children power toward a reflexive methodological approach that captures how power is exercised in design with children, what effects it has, and its different scales.

PD researchers have previously proposed that power is exercised through deliberate decisions claiming that "decision-making is the exercising of power" [8] (also [7]). The exploratory character of Gallagher's research, however, shows that power can also be expressed in the absence of obvious decision points, demonstrating how child participants employed subtle ways to limit the voices of their peers while sharing their experiences, or to change the research foci. This discursive manifestation of power becomes particularly relevant during the early 'problem setting' phase of design where the aim is to explore problem dimensions, and frame a design problem as opposed to inform concrete design decisions grounded in a material artefact. It is thus not surprising that PD researchers have often used ethnographic and verbal methods during the early phase of design given this exploratory orientation [45].

In contrast to the ideation and prototyping phases of design, less attention has been given to how participation and power are performed in this early design phase [45]. Importantly, it is in this phase where assumptions about a design problem are challenged, and the orienting values underpinning technology design begin to emerge [26]. Upon identifying this research gap, Halskov and Brodersen Hansen [25] raise the question of who is engaged in the interpretive work, while asking for transparency on how this early, problem setting research informs the following ideation phase. This is further illustrated in Bossen's [7] 
cautionary account of PD for digital medical records. The author reflects on how the board commissioning the research had misinterpreted research participation outcomes by neglecting certain groups' experiences. Bossen problematizes the lack of power participants had over these interpretations. With regards to developmentally diverse children, two systematic reviews of the current research landscape suggest that children do participate in the problem setting phase of design, primarily through interviews and observations $[4,6]$. However, it is often left unclear how this participation informs design and the power dynamics that underpin the design process [4].

\section{RESEARCH QUESTIONS}

We present two separate case studies involving (i) children with dyslexia, and (ii) children with cerebral palsy in design. Following Bratteteig and Wagner [8], both case studies were grounded in the belief that a PD process must involve children as active participants to inform the definition of the design problem. In both case studies we identified problematic power dynamics - spanning from children not replying truthfully to our questions, to the researcher exerting tight control over the direction of the session. At times these dynamics became a barrier to how much children could inform the direction of the project, and prompted us to recognise the need to reflexively engage with the issue of power. Past research designing technology with and for developmentally diverse children has often been couched in an unchallenged empowerment claim to promote children's voice and share power over design decisions (see $[4,6])$. In applying a sociological lens on power, we move away from the assumption that power is shared with children to examine the manifestation, conditions, and consequences of power dynamics when two different groups of developmentally diverse children participate during the early problem setting phase of technology design. This overarching research goal is addressed through the following questions:

- RQ1: How does power manifest in the context of the enablement agenda and the early stages of design? How do children with disabilities in particular exercise power?

- RQ2: What contextual factors shape the power dynamics between the children and researchers?

- RQ3: What are the consequences of these power dynamics on children's empowerment to inform the early problem setting phase of design?

To answer these research questions, within each case study we present a descriptive account of the power dynamics unfolding between children and researchers (RQ1), and the context in which they occurred in (RQ2), with additional interpretive analysis appearing in the Discussion section to reflect the relationship between power dynamics, their context and their consequences with respect to the design goal pursued in each case study (RQ3).

\section{CASE STUDY 1: A READING APP FOR STUDENTS WITH DYSLEXIA}

\section{Methodology}

\section{Context and assumptions}

The first case study we present was a one-year project funded by an industry Innovate UK funding call entitled 'design for impact'. The aim of the call was to introduce new technologies in education designed with user partnerships. It is in the context of this call that we planned to design a reading app intended to support students with dyslexia. Between $8-10 \%$ of children in the UK, which was the context of the research, are diagnosed or suspected to have a learning difficulty that primarily affects the skills involved in accurate and fluent word reading and spelling [40]. Dyslexia is a learning difficulty that occurs on a continuum rather than as a distinct category, as each individual 'struggling reader' is likely to experience a subset of many associated difficulties $[10,40,43,46]$. We focused on students in primary school (elementary, i.e. 8-11 years), or early entry to secondary school (high school, i.e. 12-13 years). This 
constitutes a critical stage in children's education as the academic expectations increase rendering children's difficulties more challenging at a time when special education provision also decreases.

Key to the design concept was the idea of supporting children's reading motivations, while also offering in the moment support in the literacy areas they found challenging. Evidence based practice suggests that literacy teaching for difficulties decoding print is most effective with explicit and systematic methods aimed at developing children's strategies for tackling word reading [24,43]. A key barrier that teachers report, particularly with older children, is children's lack of motivation to engage in reading [36]. Alvermann [2] shows through a case study of a struggling reader that the personal relevance of narrative plays a critical role in how struggling readers engage with the written form. Since interest in an activity has been found to foster intrinsic motivation [32], teachers will often embed children's narrative interests within literacy activities. In summary, our initial reading of the design problem was couched in the logic that literacy and word decoding (as a skill) is critical in increasing social and employment opportunities. Building on children's narrative preferences could potentially support their motivation and love for reading, which combined with explicit teaching could support improved reading skills.

\section{Project participants, roles and expertise}

The project funded two partners: an academic partner with expertise in dyslexia, as well as PD; and an industry partner with expertise in developing assistive technology. The project was conceived and initiated by the academic partner. The academic partner's role was to create and run a series of design workshops that supported the development of a prototype. In keeping with a reflective design process there was a general exploration of the design problem to support an understanding of the problem setting, followed by hands-on prototyping activities with the children [42].

The workshops took place in classrooms involving a group of children and the researcher, i.e. the academic partner. The two schools initially involved were (i) a specialist dyslexia school and (ii) a mainstream primary school in London, UK. Within the specialist school, children participated in daily literacy lessons in small classes with other children who struggled with literacy. Five children ( 3 male, 2 female) engaged in the research. Throughout the process, there was a mutual understanding of the problem the researcher and children defined, and a clear link with the design concept subsequently created. In contrast, in the mainstream school we found it particularly challenging to interpret children's contributions. The complex relational dynamics observed in these children's interactions prompted us to focus our analysis on the mainstream school workshops only.

Participants from the mainstream school were four boys aged 8-10, two of their parents (both female), the children's special education teacher and the school's SEN coordinator (both female) who oversaw the children's support. All of the children had been identified due to familial risk of dyslexia that had an impact on their literacy. The children received weekly support in the form of personalized literacy sessions run in small groups outside mainstream provision.

\section{Researcher orientation to child involvement}

Similar to other PD research with developmentally diverse children [4], our design process was constrained in time span by the school's timetable (also [23]). This limited our sessions to three one-hour workshops. Though this limited the frequency and scope of participation, we were aligned with a PD epistemology that sought to privilege the child's voice and participation. Involving the adults was done to enrich and build our understanding of children's contributions. Moreover, as argued earlier, we wanted to co-develop the dimensions of the design problem with the children following Bratteteig and Wagner [8] who argue that a participatory process must involve users to take part in the 'big decisions like defining the problem'. 


\section{Data collection and analysis}

Given the aim of our paper to explore how power manifests in the early phase of design, our analysis focuses on data collected from the first workshop. We video-recorded the 1.5 hour session by placing a video camera in front view of the table at which the children were sat. In addition to the video, we kept reflective notes of the session to capture our interpretations of the interactions we had with the children. We also held 30 minute semi-structured interviews with two of the children's teachers and two of the children's parents. The focus of the interviews was to broadly discuss each child's learning profile and interactions with digital/non digital learning opportunities, toward gaining an additional perspective on each child. Whilst video analysis was our primary focus, where possible, the notes and adult interviews were consulted to enrich our descriptive and interpretive analysis.

Our video analysis approach was informed by Derry et al [53]. Whilst watching the video repeatedly to deeply familiarize ourselves with the data, we sampled from the video to identify significant moments, i.e., critical events. Given our research aims, a critical event was defined as a moment where participants, or researchers, exerted power over each other. Following Foucault's account of power, we focused on interactional moments where the child, or researcher, applied some form of action in response to their interaction partner's action, impacting on what followed.

This yielded a set of 26 critical events, which were transcribed. We conducted a combination of deductive (top down) and inductive (bottom up) analyses. Deductive analysis is especially appropriate when theory has been developed in prior empirical research and is used as a framework for analysis. Inductive analysis is appropriate when the researcher seeks to generate new theory derived from the data, especially when an area of research is under researched. We used Gallagher's findings [21] deductively to identify specific instances of power. For example, we looked for evidence of adults coaxing children to attend to the design task, or adult intervention in activities that were dominated by certain children. However, given that Gallagher's prior research was not carried out in the context of co-design or with disabled children, we also took an inductive approach. In line with our broader theoretical scope on power, we paid particular attention to the interaction dynamics and actors involved, as well as the consequences of power dynamics in context to generate new descriptive codes. Next, deductive and inductive codes were thematized and themes were progressively refined as we reviewed the data following a thematic analysis approach [54]. In addition to the reported themes, we return to key theoretical concepts from our literature review on power, such as scales of power, consequences of power, as well as PD concepts, such as empowerment, to expand on our interpretive analysis in the Discussion section.

\section{Findings}

\section{Challenging assumptions embedded in the design problem}

Core to the research proposal was the belief that children had narrative preferences that new technology could enrich. This perspective was particularly important in departing from a primarily remedial focus by grounding the process of reading in children's narrative preferences. The first activity was a focus group where we asked children about stories they enjoyed. Through such questions we aimed to understand their existing narrative preferences. A visual probe, i.e. a laminated poster with a set of concrete examples of book genres, was used to support this discussion. During the discussion, however, children stayed mostly silent, appearing unsure when providing answers and often mirroring the researcher's language (see Excerpt 1). 
Attempting to mitigate the perceived misalignment between our questions and children's responses, we employed indirect questioning [44]. For instance, we probed children to share whether their teacher asked them to check out books from the library toward identifying which ones they were currently reading, or provided an example of a popular book as a prompt to discuss their views on the book. Children were animated when sharing how their peers engaged with the book and joined in to explain the rules of book borrowing at their school. However, they did not reveal their own narrative engagements. When triangulating children's responses with follow up parent and teacher interviews, we were supported to reflect upon these interactions. As one parent bemoaned: "He won't pick up a book, books don't interest him, even though I force him to, they don't interest him; not one bit. You have to shadow him to get him to do something with regards to academic." It became clear that the children involved in the research rarely read books, and when they read, it was extrinsically motivated by an adult.

\title{
Children's disclosure strategies
}

One of our aims was to co-evolve the design problem with children's input. Due to the children's young age and thus limited metacognitive capacities to reflect on their own learning [40], we made the decision to scaffold the discussion with pre-defined scenarios. Drawing on previous empirical research with struggling readers, also corroborated through our workshop with the older children at the specialist dyslexia school, we constructed four problem definitions that reflected aspects of struggling readers' experiences in the classroom in the form of brief scenarios. We started by explaining to the children the importance of their involvement in the problem setting phase of design. Next, we prompted them to reflect on each scenario's relevance to their own learning experiences and prioritise its importance in the next design phase.

Some of the scenarios we presented could be interpreted to reflect young children's journey toward becoming independent learners, e.g. struggling in class with a particular topic, keeping track of homework. All of the children but one (Drew) quickly connected these scenarios to their own experiences, shared the supportive environment of their school that scaffolded them, and asked to prioritise them in our next design session. Conversely, when we introduced scenarios that were associated with reading difficulties, such as struggling to keep up with long texts, children's disclosure strategies varied. Sometimes they acknowledged that the scenario was relevant to themselves, albeit hesitantly as their non-verbal communication expressed a sense of uncertainty, for example by pausing or avoiding eye contact with us. In one occasion, two of the children, Drew and Matt, shifted the focus of the scenario away from themselves to a third classmate with more severe learning difficulties.

\section{Excerpt 1 - Discussion of reading preferences}

\author{
Researcher: What books or stories do you like to read? \\ Drew: Funny. \\ Researcher: $\quad$ Funny? Can you give us an example of a funny book maybe that you - comes to mind? \\ Drew: $\quad$ Tom Gates? (name of author) \\ Researcher: $\quad$ Tom Gates? Anybody else? \\ Matt: $\quad$ Scary films? Um, no scary books. \\ (Jon and Nat are avoiding eye contact with the researcher) \\ Researcher: $\quad$ Scary books? You Jon, any ideas? (picking up the book genre probe) We have a few ideas here just to give you a starting \\ Jon: $\quad$ Yeah. $\quad$ Yeaht. \\ Researcher: $\quad$ Which book comes to mind for - \\ Jon: $\quad$ (points to one of the pictures of a book title included in the probe) \\ Researcher: $\quad$ This one? The 'Diary of a Wimpy Kid'? \\ Jon: Yeah. \\ Researcher: $\quad$ Have you read this one, or do you know of that book? \\ Drew: The 'Diary of a Wimpy Kid', yes, I've watched the movie as well.
}


One of the participants, Drew, throughout the session had regularly asserted his reading independence. In this part of the workshop he sharply pointed out that the scenarios did not concern him. Whenever the other children began to open up about the school experiences they faced with respect to their learning profile, Drew's dismissals of the same challenges introduced a division within the group. Often Drew's responses prompted the other children to change theirs, or to stop short in sharing their thoughts. In a later interview with the teachers, they disclosed that Drew struggled to negotiate his learning identity, creating a barrier to their support.

Children's diverse disclosure patterns had a profound impact on our facilitation. We found ourselves wanting to respect Drew's voice and by extension his rejection of our aims, while recognising that the wider group found some scenarios important to address. For example, when Drew rejected a scenario the rest of the group had prioritised, we attempted to legitimise both perspectives: "okay, maybe we have a split. For some students perhaps we need to think about it [the scenario] and for some we don't". Moreover, when other children's voices were limited by Drew's interruptions, we chose not to prompt these children to open up in an attempt to avoid the polarisation we perceived.

\section{Tangents as strategic tools and moments of insight}

Throughout the session there were often tangential discussions to the main research theme. Given the moments of hesitance we observed, sometimes we promoted tangents as a way to encourage children's disclosure. For example, when one of the children chose the Diary of the Whimpy Kid book connecting it to a recent movie (Excerpt 1), we asked the group to share the plot with us. These 'interventions' were readily taken up by the children who enthusiastically contributed to these conversations. Yet, they had little impact on encouraging the children to open up when we returned to the main workshop topics. Tangents were also introduced by the children. For instance, while Matt provided a book title as a context to describe his reading experiences, Jon interjected to critique the plot of the book leading the conversation toward a new direction. We found ourselves managing a balance between listening to children express themselves vividly during these occasions, and wanting to bring them back to our line of questioning given the little time we had with them.

While tangents were often recognisable due to their clear departure from the workshop themes, sometimes they were subtle as children re-interpreted our questions in new ways that were meaningful to them. For instance, when asked whether they play games for literacy, one of the children Nat exclaimed 'I invent games!' suggesting that his motivations lay in creative forms of digital literacy. Adding to this account, Matt's mother explained how her son's engagement with Minecraft had supported the development of new vocabulary and subsequently supported sight word reading of advanced Minecraft books. When pursuing our goal to understand children's reading motivation, three out of the four children identified books that were also TV series or movies. These instances could have foregrounded a transmedia account of literacy in which different media act as external catalysts to struggling readers' print literacies. However, the potential insight these moments offered was overlooked in keeping with the original scope of the project.

\section{CASE STUDY 2: CHILDREN WITH CEREBRAL PALSY AND THEIR SGD}

\section{Methodology}

\section{Context and assumptions}

The second case comes from a postgraduate (Masters) project aiming to involve children who have severe cerebral palsy $(\mathrm{CP})$ in the critical evaluation of their existing communication aid technologies. $\mathrm{CP}$ describes a non-progressive neurological disorder of movement and posture that affects approximately one in every 400 children in the UK [1]. Many children with CP are known to have a range of other 
disabilities that co-occur with physical disability such as learning and language difficulties. Within this group, approximately $36 \%$ have motor speech impairments [37].

Owing to severe speech and physical difficulties, children who have severe CP adopt 'other ways of speaking' [47] through non-verbal / un-aided communication methods including kinetic modalities. These children's language and communication skills can be supported through the introduction of aided communication methods. These include 'low-tech' tools such as books and charts displaying grids of pictures, symbols and/or words (depending on the child's level of symbolic understanding), and 'hightech' speech generating devices (SGDs) which offer large vocabularies and grammaticalisation functions, again with language presented to the user as grids of pictures, symbols and/or written words. These tools are intended to help people who otherwise have little or no functional speech to communicate and learn language.

Although SGDs provide solutions for some non-verbal children and adults, giving them the power of voice, one third of these devices are abandoned within one year of provision [29]. A major reason why they are rejected concerns their usability, with devices that fail to meet people's diverse functional communication needs [51]. However, there are also suggestions that devices are based on 'best guesses of what a non-disabled person may want' [31] without integrating basic tenants of HCI such as user values. Drawing on the personal experience of the researcher, this Masters study started with the viewpoint that children can struggle to use these technologies to communicate. Our research goal was to understand the particular experiences and challenges children had in using SGDs in order to generate new directions for improving the design of SGDs.

\section{Project participants, roles and expertise}

The project research team comprised the principal researcher, SLT faculty member and an HCI faculty member. The principal researcher was a speech and language therapist (SLT) investigating the involvement of children with severe speech and physical difficulties in defining design priorities for SGDs. Besides carrying out her postgraduate studies, she was also a staff member within the school setting and as an SGD specialist, had experience in communicating with children who use varied SGD systems. Therefore, the principle researcher held specific knowledge about how the participants in the study would typically communicate in day-to-day interactions. The SLT faculty member, whose research interests concern development in children with cerebral palsy and SGD system use in interaction, provided indirect input across all stages of the project. The HCI faculty member provided additional input across the study guiding the research methods.

The participating school was a special school in London, UK. Two children were involved, both female, aged 6 and 11, who had severe CP. The children were known to the researcher through clinical work. They relied on a carer to support them with all physical activities of daily living and used supportive postural equipment. Both were children who used SGDs and paper-based communication books that represented language through colour picture communication symbols (PCS) [59] organised into topic categories. The children indicated their choice of symbol on the paper-based system by using systematic and purposeful looking behaviours. An (adult) partner would hold up their communication books at eye level and the children would use their gaze to direct that person's attention to the symbol of choice. It can be difficult to identify accurately the specific focus of gaze in a crowded display of symbols so on occasion the partner may also read out the meaning associated with symbols in the general area in which the child fixed their gaze and the child would confirm when the correct one is spoken. Both children signalled 'yes' and 'no' through gesturing (nodding or shaking their heads), or by eye pointing [41] towards a relevant 'yes' or 'no' symbol. Each child also had an eye-control SGD. Eye-control technologies track the location and movement of a user's gaze, translating this into cursor control to provide access to the device. Each session 
took place in a quiet room outside of their classroom and it included the researcher and the individual child.

\section{Researcher orientation to child involvement}

Given the principal researcher's daily access to the children, there was an opportunity to involve each child in four individual sessions allowing an in-depth investigation. Similar to case study 1, the view was taken that children's voices should inform the problem setting. Each session was driven by the same goal to gain a rounded understanding of each child's experience with her SGD through different types of activities e.g. vignettes, trials of technology etc.

\section{Data collection and analysis}

Our analysis includes data collected from the eight sessions. The average length of each session was approximately 22 minutes. We ran four short yet regular sessions for each child to minimise the risk of fatigue which can be common in using eye control SGDs [55], and to limit disruption to children's school days that were already heavily filled with therapy sessions, personal care routines on top of their time in class. Similar to the first case study, we video recorded each session by placing a video camera in front view of the physical area each child occupied. The researcher also kept reflective notes of the session documenting the dynamics with each child during the activities and interpretations thereof. The notes were triangulated with the videos to enrich the analysis.

The analysis generated 62 critical events across eight sessions (Abigail 33, Danielle 29). These events were time stamped and transcribed so that we could refer back to them within the context of the session. The events were analysed in line with the deductive and inductive method described in case study 1 . This approach allowed us to progressively thematize the events toward investigating our goal to understand how children exercise power during participatory activities and what consequences this had on subsequent actions.

\section{Findings}

\section{Challenging assumptions about the type of participation}

The first session began with an unstructured conversation initiated by the researcher centred on the child's interests. This acted as a 'warm up' activity to build rapport with the researcher who was known to the child in her clinical role. Following this, the researcher described a vignette of a child who struggled to use their SGD (see Fig. 1). Vignettes were used as they provided a concrete and contextualised way of introducing topics that children may be reluctant to openly discuss when referring to their own experiences [3]. Vignettes were deemed important as they removed the expectation for children to talk about their own difficulties with their technologies, before they were ready to do so. The vignette offered to each child was varied slightly so that it could present a relatable hypothetical, with the scope of still being distanced by the third person account. Each child was asked to share her views regarding how the character in the vignette felt about a problematic situation, what the character might do next, and how they might go about this. As the goal of this session was to establish an understanding of the types of challenges that children may be facing with their SGD systems, they were also invited but not pressed to share personal experiences.

\section{Figure 1 - Vignette customised to one of the children}

I want to tell you a story about Sarah. This is Sarah in the picture. She is in Year one at school, and she finds it difficult to control her muscles and body movements, like you do. She does some things at school differently than the other children in her class but mostly, she tries to be the same as the other children. One thing that is different for Sarah is her talking. She uses pictures and symbols in a communication book, and a computer to talk with other people. Sometimes, there are things that Sarah wants to say but 
she cannot say the word... and it isn't in her communication book or on her computer. Lots of times, she has trouble finding the right word on her computer and stops using it. One day last week, her teacher said "I think that you should use your computer to take part in sharing your answers during carpet time and choosing your lunch in the dining hall."

The researcher used yes/no questions and lists of response options to ask questions about the children's devices. In principle, these strategies offered opportunities to scaffold child thinking about the issues at hand, and to offer opinions that they may not have considered previously, or may not have been asked to consider. This approach also minimised potential problems with children's lack of access to relevant vocabulary on their SGD. However, while shown to be effective in some contexts, for instance in the case of people who have recently experienced traumatic brain injuries and need to re-establish a consistent 'yes' and 'no' [16], problems were also evident with this approach. This is illustrated in Excerpt 2. In response to questioning, Danielle appears to indicate that her SGD is difficult, but not boring (to use). However, when asked whether it is fun to use, the researcher treats Danielle's responses as signalling both yes and no. While ultimately both researcher and child appear to settle on the idea that the communication aid is fun, the difficulties encountered in negotiating the meaning of Danielle's responses raises a number

\section{Excerpt 2 - Child's conflicting responses to the vignette (D: Danielle, R: Researcher)}

R: Umm, do you find it difficult to use your communication aid for a different reason?

D: (briefly pauses, looks ahead. The eye points to 'yes')

R: $\quad$ Is it boring?

D: (Shakes head 'no')

R: $\quad$ Is it fun?

D: $\quad$ (looks downwards to her tray in direction of 'yes' symbol, eye points to 'yes' symbol held at her eye level and shakes head 'no')

R: $\quad$ Yeah? You're looking at 'Yes'

D: $\quad$ (shakes head 'no' again')

R: $\quad$ Is it fun using your communication aid?

D: $\quad$ (drops her head to her chest and looks down, past her tray to the floor)

R: I know, I've asked you that lots of times, it's 'cause you were shaking your head like I thought you meant 'no'. That's why I keep asking you the same question.

D: $\quad$ (eye points to 'yes' then back at the researcher)

R: It's fun, ok. Umm, do you think your communication aid has fun things on it to talk about?

D: $\quad$ (fist points and eye points to 'yes')

R: $\quad$ Yes. Could there be things on it that are more fun to talk about?

D: $\quad$ (eye points to 'no')

R: $\quad$ No? Oh. Do you think it's got enough fun things on there? (Danielle smiles as asking question)

D: $\quad$ (looks away, doesn't respond to question)

R: (laughs briefly then puts down symbols) Alright. Let me ask you some different things.

of concerns about the strategy.

In this example, it is possible that Danielle didn't understand the question, or that she wanted to indicate that she was getting bored (as hinted at by the researcher saying she was aware she had asked the question lots of times and explaining why she was confused by Danielle's response). Perhaps the question was not relevant to how Danielle was thinking about her device, or that she did not ascribe the same meaning to the adult options offered to describe how children feel about their technology. Perhaps Danielle wanted to say it is both fun and boring. The possibility that closed responses may not have captured the child's communication intentions was clearly evidenced with one of the children who did not want to 'play some more', but also didn't want to 'stop'. Similar to case study 1, we attempted to clarify children's intentions, but were unable to establish the specific meaning of their actions. Thus, children's agency and thus power over the conversation and our joint interpretation of what was discussed was undermined by the approach we took. Our efforts to mitigate this through clarification strategies did not bring clarity. 


\section{Tangents as moments of insight}

In case study 1 , we showed that tangents served as a strategic tool used by the researcher to encourage children's disclosure when they hesitated to engage in the workshop themes. Conversely, in case study 2 , tangents were only initiated by the children. Given children's severe learning difficulties and limited attention we attempted to retain tight control over their turn-taking and conversation autonomy in order to ensure the interaction remained focused on the research questions. Despite those efforts, when children's goals clearly diverged from our own, often their attention to the main task was impacted and the child was no longer focused on the research task. For example, one child, Abigail, had described the vignette character as bored. This motivated the researcher to ask why the vignette character might be feeling 'bored' with her SGD. However, Abigail's attention and body movements redirected the focus of the action to a colouring activity. After repeatedly directing vocalisations to the researcher indicating her desire to access the pens, the researcher conceded and accepted Abigail's request to engage in a drawing activity.

In the later sessions the researcher presented children with a series of short experiential activities where they were introduced to an SGD layout (see Figure 2). The sessions were loosely structured and involved trialling the new layout that organised words and language within a schematic visual scene display, as opposed to the grid-based layout used by the children. The visual scene display presented a picture or photo scene that represented language concepts within so called 'hotspot' areas on screen. These would be spoken by the device when activated by selecting the highlighted area. The focus on visual scenes was motivated by work suggesting that these scenes may reduce demands on young SGD users as they exploit rapid visual processing of naturalistic events/contexts as opposed to isolated symbols [52]. The experiential visual scenes activities were important for addressing the research goal as they offered an alternative way for the child participants to interact with language in context, that was different to existing SGDs that semantically organised language into categories presented as grids of symbols.

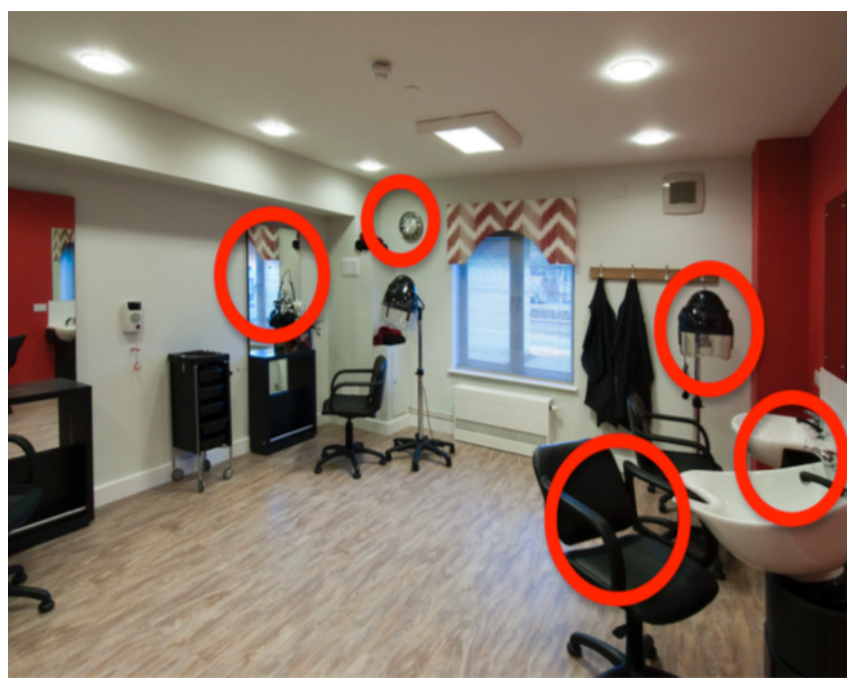

Figure 2. Image of a salon visual scene expressing one of the children's interest in getting her hair styled with hotspots of language representing 'washing', 'drying', 'sitting', 'time' and 'mirror' 
Unlike early sessions which centred on involving each child in a dialogue about the vignette and themselves, these sessions were organised as loops between using the technology and giving feedback. We offered children opportunities to trial the visual scene displays that were linked to knowledge we had on children's interests. For example, Figure 2 presents a photograph of a pretend play 'hairdresser salon' scene we customised for Abigail who loved styling her hair. The two children were invited to interact with these independently, at their own pace, minimizing the pressure for them to respond verbally. Following each loop, the child and researcher sought feedback that was discursive in nature, moving between what children thought of the visual scenes and what content they might like to see conveyed through visual scenes in future sessions. While the researcher's aim was to evaluate the usefulness and usability of the layout, the researcher was drawn into a series of play-based activities initiated by both children who interpreted the situation in a new way. For example, in Excerpt 3 in what seemed at first to be a communication request, Abigail, initiated and then facilitated pretend, make-believe play with the researcher. As the play situation (and the researcher's responses) became more playful and absurd, Abigail also became more animated. Similar to case study 1, tangents moved away from what we wanted to learn towards activities that were important to the children. In the case of Abigail, tangents reflected her motivation to physically and independently act ("I do it"), the importance of play, and her interest in creative/craft activities.

\section{Excerpt 3 - Children's power over the direction of the session (A: Abigail, R: Researcher)}

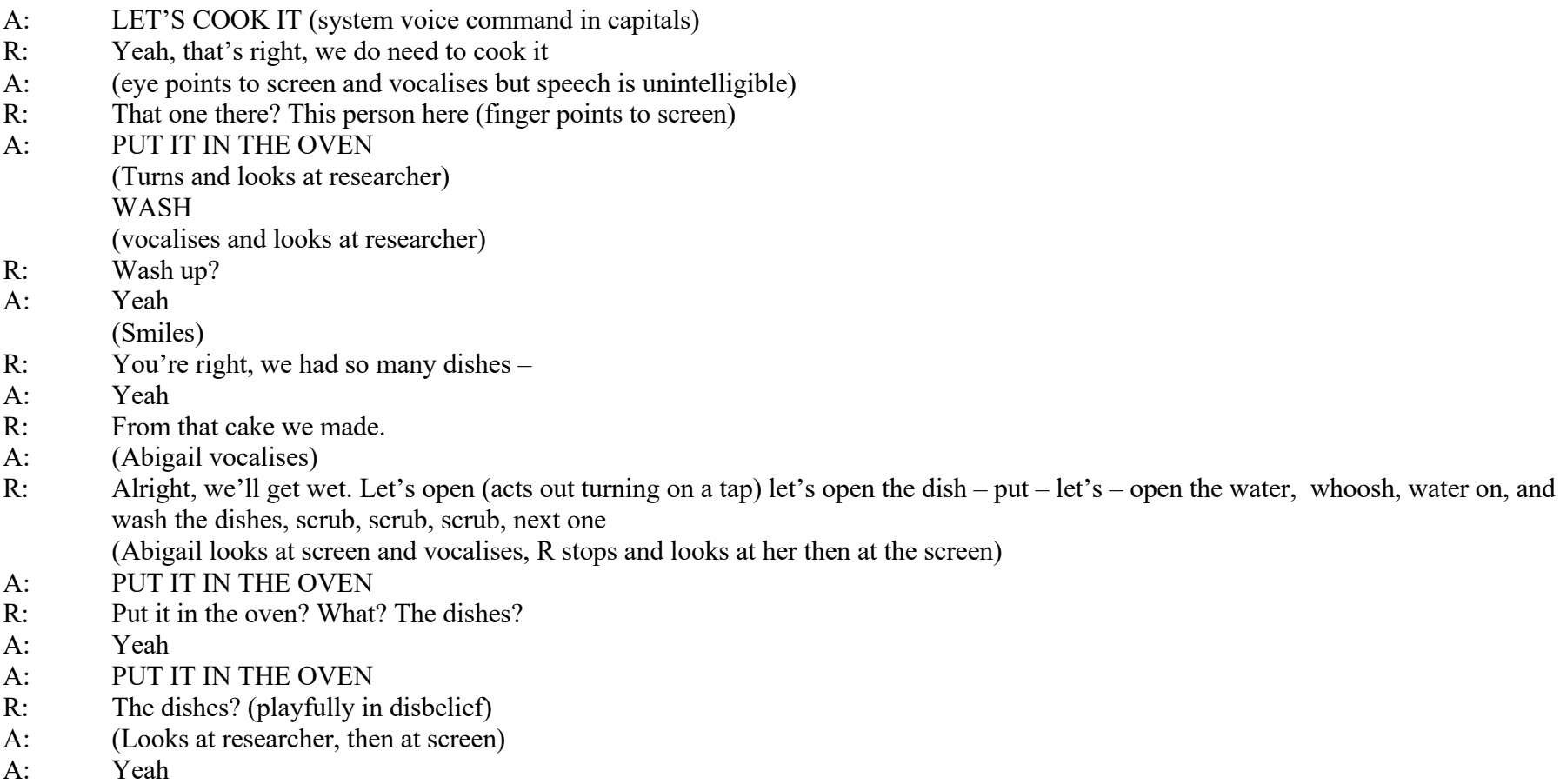

\section{Power as a result of moving between different roles}

Having worked in the school prior to the study and consequently being an insider researcher was assumed to have its benefits. The researcher's familiarity with children's idiosyncratic communication practices and related healthcare routines meant that she was already sensitised to dealing with issues of saliva management, uncontrollable bodily actions, difficult to interpret communication, and other features associated with CP. In acknowledging and dealing with these features as part and parcel within interaction, the researcher intended to develop a trusting relationship with the children by conveying that she already 
held some knowledge and experience of their experiences as users of SGDs [1]. This prior experience also meant that the researcher was able to interact with the two children unsupervised, as agreed with the school and their parents. However, it also necessitated a constant shift between the roles of researcher and carer where forms of power appropriate in the role of care inadvertently carried over into the research relationship.

For example, during a session with Danielle, the researcher attended to her gastrostomy feeding pump as it continuously beeped upon reaching the end of her feed. Whilst the researcher asked Danielle a series of 'yes' and 'no' questions about the story vignette that they had been looking at, the beeping pump redirected their attention. In the interaction, Danielle turned her head to look over her left shoulder towards the sound, as the researcher interpreted this as a call to respond. The researcher verbally let Danielle know that she was acting on this by asking a question: "Shall I have a look?" and advanced without waiting for a response. In contrast, in her questions leading up to this, the researcher had offered Danielle more time to respond in varied ways and had overtly acknowledged any difficulties in understanding what Danielle was expressing. Following this episode, the researcher returned to asking questions about the vignette with the expectation that Danielle will use the 'yes' and 'no' symbols that were held up in front of her to respond, which Danielle did.

The action of switching off Danielle's feeding pump because it no longer needed to be on was intended to put Danielle at ease by implicitly communicating to her 'this is not a problem, I know what I'm doing, let's carry on'. Yet, it also reinforced an authority over Danielle's personal care, introducing an element of power over her body. As the researcher quickly switched back to the role of the 'questioning researcher', her power over Danielle's actions carried over in the researcher's directive follow on actions. Prior to caring for Danielle, the researcher questioning had been less directive, inviting Danielle to respond in this way yet being open to wider communicative actions. Following this, the researcher now directed Danielle to make a fixed choice between two symbols demonstrating power over the interaction.

\section{DISCUSSION}

At the core of PD is the idea of sharing power with participants throughout the design process. The sharing of power starts from the problem setting stage where end users and researchers together evolve the design problem e.g. $[7,8]$. Through our empirical work with two PD case studies with developmentally diverse children in this phase of design, our goal was to understand how this power negotiation occurs in the context of the enablement agenda. Our research questions focused on (i) capturing the dynamics at play between children and researchers (RQ1), (ii) the context shaping these dynamics (RQ2) and (iii) the impact this has on how this group of children inform the early problem setting phase of technology design (RQ3). The discussion that follows builds upon our findings in order to draw the implications of power for designing technologies for disability, as well as configuring design processes with developmentally diverse children.

\section{Power dynamics in the context of the enablement agenda and their consequences on design}

Previous research in the field of child-computer interaction has often aligned with an enablement agenda seeking to design technology that supports developmentally diverse children with their functional skills toward ensuring inclusion $[4,19]$. In doing so, researchers have engaged children in the early phase of design. However, as [4] report, whether children's participation informs decisions is often left unreported. With both our case studies aiming to broadly support children with their functional skills, our goal was to involve them in the problem setting phase of design through the use of direct methods. When defining a problem or an opportunity space to design for, designers focus their initial thinking on specific dimensions about people and their contexts to begin to frame the problem [42]. This thinking is further shaped through the involvement of users in research. In both cases we started with a set of tentative assumptions: that 
children were moved to read certain narratives (case study 1), or that they faced challenges in using their SGD (case study 2). We also anticipated that children would be willing and able to participate in the sessions.

Across both case studies, children often remained silent, or provided ambiguous and conflicting responses. In case study 1, rather than question the relevance of our assumptions, children attempted to align themselves with us, even though our contact with teachers and parents revealed that reading books and exposure to book narrative was distant from their everyday lives. The same group of children demonstrated reluctance to share details of their challenges with learning and identify the most pressing problem dimensions to take forward into further sessions. In case study 2, it became unclear if the children involved were unwilling or not able to reflect and answer questions about the topics posed. The two researchers used similar techniques to build rapport with the children and to clarify their responses, but this proved to be ineffective. Table 1 summarises these relational behaviours. Despite the children cohorts and lead researchers being different in each case study, our study demonstrates that, on the surface, their relational behaviours are strikingly similar.

Through their inaction and action, it could be argued that children exercised power over how researchers carried out the session and the researchers' certainty in their assumptions. When examining the consequences of this power, however, it is difficult to claim that this process empowered children. In practice it proved challenging to gain insights that would evolve our design thinking. Therefore, our reflexive examination of power revealed that despite our best intentions, the outcomes of children's power were negative and children were not empowered to participate in the design process. In adopting the view that power is contextual and situational $[20,21]$, we now reflect on the contributing contextual factors underpinning these dynamics in order to identify implications for configuring future PD with developmentally diverse children that is supportive of the enablement agenda.

\section{Contextual considerations when designing for enablement}

Power relations are often nested between research project participants, other actors and institutions ultimately impacting on the nature of power and its consequences [21]. For example, Iivari et al [58] reflect upon school children's extrinsic commitment to school activities and their unequal power dynamics with adults to ask whether genuine commitment in PD can be achieved within the school context. Our research was part of a wider web of power relations within the school context where we had chosen to carry out the research. In order to run the PD sessions, children were removed from the class during learning time by either the SEN coordinator (case study 1) or the SLT (case study 2). Our participants were accustomed to being taken out of class to receive additional support either in groups, or individually. Removal from the classroom expressed to their peers the different learning identity of the child and was associated with remedial activities [2]. Given the focus of both case studies on functional skills, as well as the way in which access was managed, this association may have been reinforced. In case study 1 it quickly became clear that one of the children, Drew, set himself apart from this identity. Not only did he regulate his own participation by rejecting the personal relevance of the research themes, but in doing so he expressed power over the other children's disclosure. In case study 2, the researcher - who also acted as children's SLT - had embarked on the research with the aim of changing the existing power relationship she shared with the two children. However, while fluidly switching between the role of carer and researcher, she unwittingly constrained children's options to contribute by transferring remedial norms and thinking into the research.

The choice to conduct the research at schools poses trade-offs that are challenging to reconcile. In case study 1 , in contrast to the dyslexia specialist school we had also involved, the children in the mainstream school did not have the benefits of personalised private tuition and Drew in particular was identified by his teachers as the most marginalised child. We reached a challenging group, but the way in which access 
was managed may have reinforced some of the conditions that were socially disabling to the children. In case study 2, while the researcher's familiarity and understanding of the children supported pragmatic aspects of the research, it proved difficult to overcome cemented and unconscious power dynamics, which at times limited how children were supported to participate. Our reflections, thus, highlight the importance of recognising and avoiding the re-enactment of entrenched power dynamics that inevitably take place in the school context.

Our study also raised a potential concern about the way we normatively defined the child 'participant', i.e. a child willing and able to engage critically and reflectively on the enablement logic. Landner [30] argues that the strongest empowerment comes from a design process shaped and led by disabled people to solve their own problems. However, Landner's account of design roles implies a self-actualisation that may first require ownership, acceptance and understanding as well as a sense of efficacy over one's situation. Children's lived experience of disability may not have prepared them to take the role of 'participant', nor was our design process orchestrated to prepare them in this respect. Had the children been prepared to inhabit this role, it is also not certain they would have chosen to align themselves with our agenda. In tandem, these reflections highlight the ethical nature of designing for the enablement agenda as it relates to the learner identities it requires children to assume. While the design of technologies that support children's functional skills remains an important way of ensuring participation in learning and social life, we thus posit that children's empowerment in design requires longer-term child-researcher relationships that foster an ethical negotiation and transcendence of children's learning identities. This stands in stark contrast with Benton and Johnson [4] who show that most PD with this population takes place over one to three sessions.

Reinforcing the importance of developing long-term partnerships with children was also highlighted by children's limited agency over the conversation, which may have been due to how we engaged with them through our methods. Direct methods of participation were seen as important to deter ambiguity over children's contributions and to ensure there was interpretive power. At the same time, direct methods may have appeared hostile especially given that some of the assumptions embedded in our questioning proved to be distant from children's lives. Though we believe the use of direct methods can potentially foster children's power by ensuring their values and needs are clearly articulated, our findings suggest there is value in using methods that have loose couplings with early designerly assumptions before gradually moving toward other direct forms of questioning.

\section{Opportunities for looking beyond functional skills}

Previous research involving children in the design process has often reported challenges of keeping children 'on task' $[35,49]$. In a similar way, in both case studies the children initiated and pursued what appeared to be tangential actions or discussions to the main research topics. Given our lens on power and participation these moments were of particular importance. Aligned to what Gallagher [21] reported, tangents were moments where children took control and changed the course of the session. They often began with an explicit point of tension between researcher-child as children used their verbal or physical 


\begin{tabular}{|c|c|c|}
\hline Contextual dimensions & Relational behaviors & $\begin{array}{l}\text { Consequences of child } \\
\text { empowerment in } \\
\text { design }\end{array}$ \\
\hline 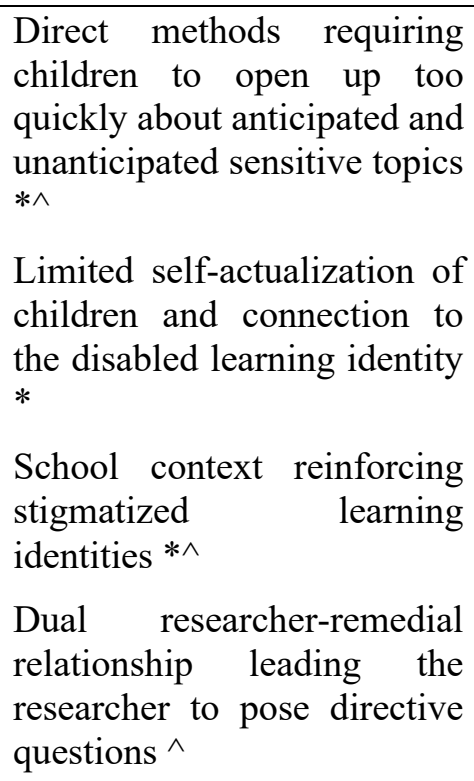 & $\begin{array}{l}\text { Children not disclosing that designer assumptions } \\
\text { were not accurate, sharing lived experiences, and } \\
\text { shifting attention away from themselves to } \\
\text { dominant narratives of others. Researcher } \\
\text { employing indirect questions to gauge children's } \\
\text { experiences * } \\
\text { One child's dismissal leads other children to limit } \\
\text { their disclosure. Researcher acknowledging all } \\
\text { children's experiences and choosing not to further } \\
\text { probe to avoid accentuating a sensitive topic * } \\
\text { Children providing conflicting responses about } \\
\text { their lived experiences with technology or their } \\
\text { learning difficulties. Researcher seeking to clarify } \\
\text { meaning of the child's response *^ }\end{array}$ & $\begin{array}{l}\text { Designers not able to } \\
\text { interpret children's } \\
\text { verbal contributions to } \\
\text { advancer design } \\
\text { thinking }\end{array}$ \\
\hline $\begin{array}{l}\text { Funder priorities and partners } \\
\text { reinforcing the focus on the } \\
\text { enablement agenda * } \\
\text { Children motivated to take } \\
\text { the lead in the discussion } * \wedge\end{array}$ & $\begin{array}{l}\text { Children reinterpreting topics or activities to bring } \\
\text { them back to their own interests, forcefully or } \\
\text { subtly } * \wedge \text {. Researcher attempting to use tangents } \\
\text { as a strategic tool to build rapport } * \text { Researcher } \\
\text { participating in the child-led interaction } * \wedge\end{array}$ & $\begin{array}{l}\text { Designers discarding } \\
\text { tangents due to their } \\
\text { relevance with respect } \\
\text { to the enablement } \\
\text { agenda }\end{array}$ \\
\hline
\end{tabular}

Table 1 - Summary of results $\left(*\right.$ Case study $1^{\wedge}$ Case study 2$)$

influence to forcefully shift the conversation or activity. In contrast to the dominance displayed during these occasions, our study showed that certain moments were malleable to children's interpretation during which children exercised power in subtle, inconspicuous ways. Though this was observed across both cases, the most notable example came from the SGD trials of a novel interface in case study 2 . The researcher had set up a task to observe how children would interact with the new language layout on the SGD and the associated challenges. Yet both children re-interpreted the task inviting the researcher to use the SGDs for play-based interaction.

Common to both types of tangents was children's leading role in shaping their own participation. Children demonstrated their power over what happened in the moment, redefined the researchers' facilitative role into a complicit listener or participant, and moved the attention away from the focus on needs relating to functional skills. Crucially, in certain moments, tangents seemed to reveal significant aspects of children's lives and their identities, contributing to the possibility of new design frames.

In case study 1, a transmedia constructionist account of literacy began to develop [9]. Children's love for creating games and game worlds led to an instrumental need and interest to use their print literacy, with print literacy forming a subsidiary outcome. In case study 2, we observed the important role of SGDs in children's play. SGD and associated usability challenges were not attributable to the child-device interaction as we had anticipated and articulated in prior work, but were managed in a relational manner between child and adult in play-based communication [28]. While children's earlier reluctance to engage 
with the enablement agenda could suggest that children hesitated to connect with the disabled identities carved out by the researchers, their tangents and their roles as active makers appeared to reveal those aspects of their identity that were important to them, echoing findings reported by Brule and Spiel [56].

Unlike the other parts of the session, during these isolated instances in which children exerted power they appeared empowered in sharing what was important to them. Yet, in both projects we treated their tangents as supporting our general knowledge of them, but also peripheral to the problem setting. Bødker and Kyng problematise the use of PD to gather requirements, emphasising that PD is a conduit to promote social change through the critical articulation of alternative futures [5]. From this perspective, tangents could have opened up a space to rethink the role of children's technology in their learning and communication and to mark a shift away from the established cognitive and remedial approach to supporting developmentally diverse children's acquisition of functional skills.

By reflecting on how relational power dynamics may shape child empowerment, our research highlights the potential to empower children by recognising the generative value of child-led tangents for disability and design. However, this recognition comes with its own challenges. In our case study 1, particularly, reflecting the scales of power, macro factors were at play as funder restrictions combined with expertise in the consortium played a critical role in how much we felt we could deviate from our funded proposal (see 'context and assumptions'). Whereas we recognised the generative value of tangents, had we shifted our theoretical focus to one where print literacy was not the central theme, we would have faced tensions keeping with our project plan, the expertise of our industry partner in assistive reading technology, and the external monitoring procedures set up by our funder. Our reflections are not unique. Vines et al [50] have previously described the role that both funders and researchers play in setting the agenda before user participation even begins. Similarly, reflecting on their facilitation of PD with citizens Gooch et al [22] observed that the procedures for managing the funding and the topic area commissioned by the funder meant that the researchers had to exercise certain forms of control over the ideas proposed by citizens. Increasingly, funders are promoting design partnerships between researchers and users. Our findings add to the growing debate regarding the challenge of negotiating power with users - especially in the problem setting phase - without a more flexible governance approach for this type of research.

\section{CONCLUSION}

PD has been previously used as an approach to develop new technology that supports developmentally diverse children's functional skills. Core to the PD epistemology is the co-production of knowledge and decisions that lead to a design outcome shaped by children and designers alike. Sharing power with children is claimed to be a critical way of achieving this. Yet, while there is little evidence of how developmentally diverse children's voices have informed design [4], past PD research more broadly shows a gap of research in the early problem setting phase of design where clear decision points are absent and thus power is more challenging to identify and mitigate. We argued that commodity accounts of power are not helpful to address the complexity of the situated interactions that occur between researcherschildren. Drawing on a sociological account of power, we recognised that power is situational, contextual and relational and thus constructed in the moment. Moreover, we moved away from a normative view of power, to one that appraises the outcomes of power for children and researchers in their context. The goal of this paper was to examine how developmentally diverse children and researchers exercise power, the contextual factors shaping these interactions, and their consequences during the early problem setting phase of designing digital technology for enabling children. Our inclusion of two different groups children with dyslexia and cerebral palsy - provided an opportunity to compare and develop a cross cutting account of power as it applies to disability and PD.

Our study shows the types of relational behaviours both children and researchers take as part of their power negotiation. Focusing on children's behaviours particularly, 'providing conflicting answers' and 
'initiating tangents' were common across both groups. Within the case study involving children with dyslexia, the group nature of the workshop introduced additional power dynamics between the children. While recognising that power is contextual, these relational behaviours may be transferable to similar design projects alerting future PD researchers to the possible dynamics they may encounter when working with developmentally diverse children. Moreover, some of the behaviours we observed have been reported in the context of participatory research and design with children more broadly and thus our research informs a broader body of work. Examples included: members of the group dominating and impacting on others' disclosure e.g. [49, 21, 58], or children's resistance of adult's regulatory tactics and resultant adultled steering e.g. [21,58]. Yet, we argue that the contextual factors that underpinned the behaviours were particular to disability. Our reflexive analysis of context raises some actionable methodological implications, but it also shows that certain contextual dimensions are deeply rooted in existing value systems and need to be recognised before they are transcended. Furthermore, we show that children's exercising of power does not always lead to empowerment. Particularly, given the stigma potentially perceived by developmentally diverse children in relation to functional skills that other children have already acquired, children's empowerment to inform design may require an explicit negotiation with learning identities. In contrast, child-led tangents offer opportunities to amplify children's voices and lead to transformative design thinking. However, the role of tangents in children's empowerment may depend on the interpretive power these tangents are afforded by the designer, alongside meso and macro nested power structures such as the extent of flexibility in project governance, or the design team's commitment to domains of expertise.

\section{ACKNOWLEDGEMENT}

We would like to thank the two schools and the participants of the study, and particularly the children, for their involvement in our research. Special thanks to Wolmet Barendregt, Laura Benton and the IJCCI reviewers whose comments improved our work. We are grateful to Duncan Brumby who provided methodological input in case study 2. Case study 1 was funded by Innovate UK under the theme 'Learning Technologies: Design for Impact'.

\section{REFERENCES}

1. Meredith Allan. 2006. AAC and Self Identity. Communication Matters Journal 20, 3: 9-12.

2. Donna E. Alvermann. 2002. Effective Literacy Instruction for Adolescents. Journal of Literacy Research 34, 2: 189-208. https://doi.org/10.1207/s15548430jlr3402_4

3. Christine Barter and Emma Renold. 2000. "I wanna tell you a story": Exploring the application of vignettes in qualitative research with children and young people. International Journal of Social Research Methodology 3, 4: 307-323. https://doi.org/10.1080/13645570050178594

4. Laura Benton and Hilary Johnson. 2015. Widening participation in technology design: A review of the involvement of children with special educational needs and disabilities. International Journal of Child-Computer Interaction 3-4: 23-40. https://doi.org/10.1016/j.ijcci.2015.07.001

5. Susanne Bødker and Morten Kyng. 2018. Participatory Design that Matters-Facing the Big Issues. ACM Transactions on Computer-Human Interaction 25, 1: 1-31. https://doi.org/10.1145/3152421

6. Peter Börjesson, Wolmet Barendregt, Eva Eriksson, and Olof Torgersson. 2015. Designing technology for and with developmentally diverse children: a systematic literature review. In Proceedings of the 14th International Conference on Interaction Design and Children, 79-88. https://doi.org/10.1145/2771839.2771848

7. Claus Bossen. 2006. Participation, Power, Critique: Constructing a Standard for Electronic Patient Records. In Proceedings of the Ninth Conference on Participatory Design: Expanding Boundaries in Design - Volume 1 (PDC '06), 95-104. https://doi.org/10.1145/1147261.1147276 
8. Tone Bratteteig and Ina Wagner. 2016. Unpacking the Notion of Participation in Participatory Design. Computer Supported Cooperative Work (CSCW) 25, 6: 425-475. https://doi.org/10.1007/s10606-0169259-4

9. Michelle Cannon, John Potter, and Andrew Burn. 2018. Dynamic, Playful and Productive Literacies. Changing English 25, 2: 180-197. https://doi.org/10.1080/1358684X.2018.1452146

10. Jean-François Démonet, Margot J. Taylor, and Yves Chaix. 2004. Developmental dyslexia. Lancet (London, England) 363, 9419: 1451-1460. https://doi.org/10.1016/S0140-6736(04)16106-0

11. Tania Di Mascio, Rosella Gennari, and Pierpaolo Vittorini. 2010. The Design of an Intelligent AdaptiveLearning System for Poor Comprehenders. In Cognitive and Metacognitive Educational Systems.

12. Allison Druin (ed.). 1999. The design of children's technology. Morgan Kaufmann Publishers, San Francisco.

13. Abigail Durrant, Jonathan Hook, Roisin McNaney, Keir Williams, Thomas Smith, Mathew Kipling, Tony Stockman, and Patrick Olivier. 2013. Design to Support Interpersonal Communication in the Special Educational Needs Classroom. In Proceedings of the 12th International Conference on Interaction Design and Children (IDC '13), 46-55. https://doi.org/10.1145/2485760.2485778

14. Marie Ertner, Anne Mie Kragelund, and Lone Malmborg. 2010. Five Enunciations of Empowerment in Participatory Design. In Proceedings of the 11th Biennial Participatory Design Conference (PDC '10), 191-194. https://doi.org/10.1145/1900441.1900475

15. European Commission. 2012. EU Charter of Fundamental Rights. https://doi.org/10.3000/1977091X.C_2012.326.eng

16. Susan Fager, Karen Hux, David R. Beukelman, and Renee Karantounis. 2006. Augmentative and Alternative Communication use and acceptance by adults with Traumatic Brain Injury. Augmentative and Alternative Communication 22, 1: 37-47. https://doi.org/10.1080/07434610500243990

17. Luciana C L de Faria Borges, Lucia V L Filgueiras, Cristiano Maciel, and Vinicius C Pereira. 2012. Customizing a Communication Device for a Child with Cerebral Palsy Using Participatory Design Practices: Contributions Towards the PD4CAT Method. In Proceedings of the 11th Brazilian Symposium on Human Factors in Computing Systems (IHC '12), 57-66. Retrieved March 11, 2016 from http://dl.acm.org/citation.cfm?id=2393536.2393544

18. Michel Foucault and James D. Faubion. 2002. In Power. Penguin, London.

19. Christopher Frauenberger, Julia Makhaeva, and Katta Spiel. 2016. Designing Smart Objects with Autistic Children: Four Design Exposès. In Proceedings of the 2016 CHI Conference on Human Factors in Computing Systems (CHI '16), 130-139. https://doi.org/10.1145/2858036.2858050

20. L.-A. Gallacher and M. Gallagher. 2008. Methodological Immaturity in Childhood Research?: Thinking through 'participatory methods'. Childhood 15, 4: 499-516. https://doi.org/10.1177/0907568208091672

21. Michael Gallagher. 2008. 'Power is not an evil': rethinking power in participatory methods. Children's Geographies 6, 2: 137-150. https://doi.org/10.1080/14733280801963045

22. Daniel Gooch, Asimina Vasalou, and Laura Benton. 2016. Impact in interdisciplinary and cross-sector research: Opportunities and challenges. Journal of the Association for Information Science and Technology: n/a-n/a. https://doi.org/10.1002/asi.23658

23. Judith Good and Judy Robertson. 2006. CARSS: A Framework for Learner Centred Design with Children. International Journal of Artificial Intelligence in Education 16: 381-413.

24. Yvonne Griffiths and Morag Stuart. 2013. Reviewing evidence-based practice for pupils with dyslexia and literacy difficulties. Journal of Research in Reading 36, 1: 96-116. https://doi.org/10.1111/j.14679817.2011.01495.x 
25. Kim Halskov and Nicolai Brodersen Hansen. 2015. The diversity of participatory design research practice at PDC 2002-2012. International Journal of Human-Computer Studies 74: 81-92. https://doi.org/10.1016/j.ijhcs.2014.09.003

26. Jonathan H.G. Hey, Caneel K. Joyce, and Sara L. Beckman. 2007. Framing innovation: negotiating shared frames during early design phases. J. of Design Research 6, 1/2: 79. https://doi.org/10.1504/JDR.2007.015564

27. Sofia Hussain. 2010. Empowering marginalised children in developing countries through $\begin{array}{lllll}\text { participatory design } \quad \text { processes. } & \text { Cosign }\end{array}$ https://doi.org/10.1080/15710882.2010.499467

28. [removed for review process]. In Proceedings of the $2018 \mathrm{CHI}$ Conference on Human Factors in Computing Systems (CHI '18)

29. Jeanne M. Johnson, Ella Inglebret, Carla Jones, and Jayanti Ray. 2006. Perspectives of speech language pathologists regarding success versus abandonment of AAC. Augmentative and Alternative Communication 22, 2: 85-99. https://doi.org/10.1080/07434610500483588

30. Richard E. Ladner. 2015. Design for user empowerment. interactions 22, 2: 24-29. https://doi.org/10.1145/2723869

31. Janice C. Light and Kathryn D. R. Drager. 2002. Improving the Design of Augmentative and Alternative Technologies for Young Children. Assistive Technology 14, 1: 17-32. https://doi.org/10.1080/10400435.2002.10132052

32. Sarah Logan, Emma Medford, and Naomi Hughes. 2011. The importance of intrinsic motivation for high and low ability readers' reading comprehension performance. Learning and Individual Differences 21, 1: 124-128. https://doi.org/10.1016/j.lindif.2010.09.011

33. Laura Malinverni, Joan MoraGuiard, Vanesa Padillo, MariaAngeles Mairena, Amaia Hervás, and Narcis Pares. 2014. Participatory Design Strategies to Enhance the Creative Contribution of Children with Special Needs. In Proceedings of the 2014 Conference on Interaction Design and Children (IDC '14), 85-94. https://doi.org/10.1145/2593968.2593981

34. Jennifer Mankoff, Gillian R. Hayes, and Devva Kasnitz. 2010. Disability studies as a source of critical inquiry for the field of assistive technology. 3. https://doi.org/10.1145/1878803.1878807

35. Emanuela Mazzone, Netta Iivari, Ruut Tikkanen, Janet C. Read, and Russell Beale. 2010. Considering Context, Content, Management, and Engagement in Design Activities with Children. In Proceedings of the 9th International Conference on Interaction Design and Children (IDC '10), 108-117. https://doi.org/10.1145/1810543.1810556

36. Sarah P. McGeown, Lynne G. Duncan, Yvonne M. Griffiths, and Sue E. Stothard. 2015. Exploring the relationship between adolescent's reading skills, reading motivation and reading habits. Reading and Writing 28, 4: 545-569. https://doi.org/10.1007/s11145-014-9537-9

37. Jackie Parkes, Nan Hill, Mary Jane Platt, and Caroline Donnelly. 2010. Oromotor dysfunction and communication impairments in children with cerebral palsy: a register study: Oromotor and Communication Impairments in CP. Developmental Medicine \& Child Neurology 52, 12: 1113-1119. https://doi.org/10.1111/j.1469-8749.2010.03765.x

38. Helen Petrie, Stefan Carmien, and Andrew Lewis. 2018. Assistive Technology Abandonment: Research Realities and Potentials. In Computers Helping People with Special Needs (Lecture Notes in Computer Science), 532-540.

39. Parvaneh Rabiee, Patricia Sloper, and Bryony Beresford. 2005. Doing research with children and young people who do not use speech for communication. Children \& Society 19, 5: 385-396. https://doi.org/10.1002/chi.841 
40. Jim Rose. 2009. Identifying and teaching children and young people with dyslexia and literacy difficulties: an independent report. Retrieved September 20, 2019 from http://dera.ioe.ac.uk/14790/1/00659-2009DOM-EN.pdf

41. Jenefer Sargent, Michael Clarke, Katie Price, Tom Griffiths, and John Swettenham. 2013. Use of eyepointing by children with cerebral palsy: what are we looking at?: Use of eye-pointing by children with cerebral palsy. International Journal of Language \& Communication Disorders 48, 5: 477-485. https://doi.org/10.1111/1460-6984.12026

42. Donald A. Schön. 1983. The reflective practitioner: how professionals think in action. Basic Books, New York.

43. Sally E. Shaywitz, Robin Morris, and Bennett A. Shaywitz. 2008. The education of dyslexic children from childhood to young adulthood. Annual Review of Psychology 59: 451-475. https://doi.org/10.1146/annurev.psych.59.103006.093633

44. Andrew K. Shenton. 2004. Strategies for Ensuring Trustworthiness in Qualitative Research Projects. Education for Information 22, 2: 63-75.

45. Jesper Simonsen and Toni Robertson (eds.). 2013. Routledge international handbook of participatory design. Routledge, London.

46. Margaret J. Snowling. 2019. Dyslexia: a very short introduction. Oxford University Press, Oxford.

47. The Communication Trust. 2013. Other ways of speaking. Other Ways of Speaking - Supporting children and young people who have no speech or whose speech is difficult to understand. Retrieved March 6, 2016 from https://www.thecommunicationtrust.org.uk/media/3414/other_ways_of_speaking_final.pdf

48. Unicef UK. 1989. UN Convention on the Rights of the Child (UNCRC). Unicef UK. Retrieved August 15, 2018 from https://www.unicef.org.uk/what-we-do/un-convention-child-rights/

49. Maarten Van Mechelen, Mathieu Gielen, Vero vanden Abeele, Ann Laenen, and Bieke Zaman. 2014. Exploring Challenging Group Dynamics in Participatory Design with Children. In Proceedings of the 2014 Conference on Interaction Design and Children (IDC '14), 269-272. https://doi.org/10.1145/2593968.2610469

50. John Vines, Rachel Clarke, Peter Wright, John McCarthy, and Patrick Olivier. 2013. Configuring participation: on how we involve people in design. 429. https://doi.org/10.1145/2470654.2470716

51. Annalu Waller. 2018. Telling tales: unlocking the potential of AAC technologies. International Journal of Language \& Communication Disorders 0, 0. https://doi.org/10.1111/1460-6984.12449

52. Krista M. Wilkinson, Janice Light, and Kathryn Drager. 2012. Considerations for the Composition of Visual Scene Displays: Potential Contributions of Information from Visual and Cognitive Sciences. Augmentative and Alternative Communication 28, 3: 137-147. https://doi.org/10.3109/07434618.2012.704522

53. Sharon J. Derry, Roy D. Pea, Brigid Barron, Randi A. Engle, Frederick Erickson, Ricki Goldman, Rogers Hall, Timothy Koschmann, Jay L. Lemke, Miriam Gamoran Sherin \& Bruce L. Sherin (2010) Conducting Video Research in the Learning Sciences: Guidance on Selection, Analysis, Technology, and Ethics, Journal of the Learning Sciences, 19:1,3-53, DOI: 10.1080/10508400903452884

54. Virginia Braun \& Victoria Clarke (2006) Using thematic analysis in psychology, Qualitative Research in Psychology,3:2, 77-101, DOI: 10.1191/1478088706qp063oa

55. Tanya Bafna and John Paulin Hansen. 2019. Eye-tracking based fatigue and cognitive assessment: doctoral symposium, extended abstract. In Proceedings of the 11th ACM Symposium on Eye Tracking Research \& Applications (ETRA '19). Association for Computing Machinery, New York, NY, USA, Article 48, 1-3. DOI:https://doi.org/10.1145/3314111.3322867

56. Emeline Brulé and Katta Spiel. 2019. Negotiating Gender and Disability Identities in Participatory Design. In Proceedings of the 9th International Conference on Communities \& Technologies - 
Transforming Communities (C\&T '19). Association for Computing Machinery, New York, NY, USA, 218-227. DOI:https://doi.org/10.1145/3328320.3328369

57. Christopher Frauenberger. 2015. Disability and Technology: A Critical Realist Perspective. In Proceedings of the 17th International ACM SIGACCESS Conference on Computers \& Accessibility (ASSETS '15). Association for Computing Machinery, New York, NY, USA, 89-96. DOI:https://doi.org/10.1145/2700648.2809851

58. Iivari, N., Kinnula, M., \& Kuure, L. (2015). With best intentions: A Foucauldian examination on children's genuine participation in ICT design. Inf. Technol. People, 28, 246-280.

59. Tobii Dynavox LLC. (2020) 'Picture Communication Symbols'. Boardmaker. Accessed 16 November 2020. https://goboardmaker.com/pages/picture-communication-symbols. 